\title{
The Relationship between Obligation to Parents and Life Satisfaction for Vietnamese American Adults
}

\author{
Chau Nguyen $^{1} \&$ Tuyen D. Nguyen ${ }^{1}$ \\ ${ }^{1}$ California State University, CA, USA \\ Correspondence: Tuyen D. Nguyen, PhD, California State University, PO Box 6868, Fullerton, CA 92834, USA. \\ E-mail: Trunguyen@fullerton.edu
}

Received: December 9, 2011

Accepted: January 13, $2012 \quad$ Published: May 1, 2012

doi:10.5539/ass.v8n6p11

URL: http://dx.doi.org/10.5539/ass.v8n6p11

\begin{abstract}
This paper presents an analysis employing the quantitative research method to study Vietnamese adult children's obligation to parents. Using primary data gathered from 95 Vietnamese American adults, this study examines the relationship between obligation to parents and life satisfaction of Vietnamese American adults. The findings indicate that obligations to parents have been adapted among the Vietnamese American adults in the sample. Different patterns of change in obligation to parents among the Vietnamese American adults are recognized. Vietnamese American adults are experiencing social, economic, and cultural challenges associated with a new life in the United States but they are struggling in ways that did not significantly alter their traditional familial obligations. The findings also demonstrate a very high level of satisfaction for the sampled Vietnamese Americans who have been Acculturalized/Americanized for about fifteen years.
\end{abstract}

Keywords: life satisfaction, Vietnamese adult children, family obligation

\section{Introduction}

The Vietnamese family has been deeply influenced by Confucius. The power of this doctrine has been incorporated into the lives of the Vietnamese people for a long period of time. It has had a profound impact on the development of the Vietnamese codes of behavior that include reverence for ancestors, respect for the elderly and obligation to parents. Due to recent mass exodus of Vietnamese refugees into the United States after 1975, the Vietnamese families are assimilating into the Western culture, embracing the ideology of individualism, and together with the economic challenge, the traditional families ties are being jeopardized.

Adult children have an obligation to their parents is a fundamental value of Confucianism. Confucianism has emphasized the family's role as the root of stability and it was incumbent on the Vietnamese people to live with such virtues as benevolence, obedience, righteousness, loyalty, and obligation to parents. The principle of "Obligation to Parents" has guided the behaviors and attitudes of the Vietnamese descendants regarding relationships within the family. However, due to recent immigration to the United States by the Vietnamese people, Americanization/Acculturalization may drastically change this fundamental value and as a result, may also affect their life satisfaction. Therefore, there is a need to focus on the relationship between the adult children obligation to their parents and the level of life satisfaction of the aging Vietnamese Americans.

The purpose of this study is to examine the relationship between obligations to parents and life satisfaction of older Vietnamese American adults. According to statistics, more than $40 \%$ of the California's current baby boomers are African American, Latino, or Asians, and one third were born outside of the country. By 2040, the majority of California's older adults are projected to be from groups now considered to be ethnic minorities. California's Asian American population is also comparatively large, accounting for about $12 \%$ of the state's population (Lee, Miller, \& Edwards, 2003).

\subsection{Historical Background}

Over 1,000,000 Vietnamese immigrants have migrated to America since 1975, when the Communists gained control of South Vietnam. This population represents the second largest group of refugees in United States history (Gordon, 1989). During the difficult assimilation into American life most Vietnamese adapted not as isolated individuals but as members of families (Hem, 1995). These families have weathered economic difficulty, 
discrimination, and cultural shock, and faced challenges to traditional Confucian ideology, which lies at the heart of their culture. Vietnamese immigrants were affected by the migration process which reshaped their roles within the family and society.

\subsection{Vietnamese Migration}

The Communist victory over South Vietnam in the spring of 1975 created a critical refugee situation. Thousands of South Vietnamese, fearing economic instability, communist reprisals, and their own physical safety, saw no alternative but to escape Vietnam. Regardless of economic class, educational background, or religion, the refugees lost most of their material possessions (Skinner, 1980). The exodus began in 1975, with the United States emergency airlift of Vietnamese military personnel and other "high risk" South Vietnamese. The rushed nature of the departure left evacuees unable to prepare for their migration. These refugees, typically educated professionals with some Western exposure, immigrated with their immediate families. Although traumatic, this group's escape to the United States was less dangerous and better organized than that of those who came later. After arriving in Guam they would then receive temporary placement in camps in the United States.

In the resettlement camps refugees began to realize the permanence of their migration and the overwhelming changes that lay ahead. In addition to instruction in the English language, the Vietnamese were exposed to an "Americanization" process which often presented confusing and conflicting views of women's roles in the family and in society (Lawyers Committee for Human Rights, 1989). Some classes prepared women to be housewives, taking care of children and shopping. Other classes at the same camp emphasized the freedom of women to pursue careers, acquire property, get divorced, and vote.

\subsection{Westernization of a Culture}

The refugees who left after 1978 experienced a different migration process. Frequently classified as "boat people" because they escaped Vietnam in small, makeshift boats, those who left later tended to be more ethnic Chinese, less educated, less exposed to Western culture, and from rural backgrounds (Kelly, 1998). Those who survived were commonly detained for long periods at refugee camps in Thailand, Malaysia, Hong Kong, and other neighboring countries before being sponsored into the United States. Refugees were initially scattered in small numbers throughout the Unites States in an effort to lessen the economic burden on any one geographical area. Anti-immigrant sentiment and isolation presented problems for these refugees. A majority of these refugees quickly migrated again to reunite with other Vietnamese and to establish a semblance Confucian extended families. Most moved to mild-weathered southern states or California. Friends and distant relatives who had been borderline members of the extended family in Vietnam often became active members within kin groups in America. These new groups became important sources of social and economic support for each other in the new land.

Gaining economic independence proved difficult for Vietnamese refugee families. Since almost all arrived without money, public assistance was necessary for the majority. Language barriers made it particularly difficult for men to find jobs comparable to the ones they had held in Vietnam, and males experienced downward occupational, economic, and social mobility. Men from all socioeconomic backgrounds faced unemployment which left them feeling powerless within the family and the community. Because of their husbands' inability to secure jobs, almost half of the female immigrants had to forsake their traditional roles and find work, frequently becoming the primary or sole wage earners in the family. Although jobs proved more readily available to the Vietnamese women than to the men, they typically were low-paying occupations such as waitressing, sales, domestic service, and food service. The deviation from Vietnamese traditional roles that occurred when women took jobs, coupled with the men's loss of economic dominance, increased the wage-earning females' power within society and the family. As women gained new control over social and financial resources, they became influential in facilitating their families' economic adjustment.

Although the families benefited from their new sources of income, this equalization of power between women and men disrupted Confucian mores and resulted in domestic tension. Husbands who had endured the loss of their economic and social status felt even less power as their wives replaced them as family providers. When child-care, traditionally the mother's role, became the father's responsibility, patriarchal patterns were further threatened. Men often reacted to this role reversal and loss of power in self-destructive, antisocial, or violent ways, and their indignation took the forms of depression, alcoholism, or spousal and child abuse. These problems disturbed the welfare and harmony of the entire family. Divorce, forbidden to women in Vietnam, became an option for escape from an unsuccessful marriage.

The refugee youths' rapid absorption into the American culture and their parents' inability to maintain strict authority exacerbated family problems. While the elders remained somewhat isolated because of the language barrier and they tended to cling to traditional values, children quickly became "Americanized" through school and 
interaction with American peers, and frequently spoke English better than their superiors. Refugees had a difficult time understanding the condemnation of striking children, since Vietnamese society condoned this practice as an effective means for parents to discipline their children. Many refugees viewed the increased rights American society afforded Vietnamese youth as serious threats to parental superiority and as obstacles to raising children.

The freedom that children gained in the United States served to distance them from their Vietnamese roots, and parents were distressed by their children's increased self-absorption and independence and their waning respect for the elders. The Vietnamese viewed these changes as threats to the solidarity and harmony of the family unit. Whereas American families encouraged children to become self-reliant at an early age and to leave home after high school; the Vietnamese viewed this independence negatively. America's freedom, which the refugees so desperately sought to obtain, was now serving to deemphasize the Vietnamese culture among their youth. While facing with overwhelming and disruptive cultural differences, the Vietnamese in the United States attempted to retain traditional, Confucius values of cohesive family structure.

\section{Methodology}

\subsection{Questionnaire Construction}

Due to the non-existence of a standardized scale to measure obligations to parents, this study's instrument was developed --a nine page questionnaire consisting of 53 questions. Most of the questions were closed ended in nature. The questionnaire was constructed in two languages: English and Vietnamese. Questions 1 to 10 in the Life Satisfaction part are taken directly from the Life Satisfaction Index A of Neugarten et al. (1961) and translated into Vietnamese and other questions were written in English then translated into Vietnamese.

The first phase in creating the questionnaire relied on suggestions of several individuals and faculty of California State University, Fullerton. In the second phase of the questionnaire construction, in order to improve the validity of translation, ten Vietnamese individuals who were fluent in both English and Vietnamese were asked to provide their opinions and suggestions about the accuracy of the meanings and cultural nuances in the wording of the questions. Those individuals were also asked to observe the time limits for completing the questionnaire (15 and 20 minutes).

\subsection{Design}

Vietnamese individuals over the age of 65 years old attending the Regent West Adult Health Care center in Santa Ana were invited to participate in the study. Written survey questionnaires and Informed Consent forms were distributed.

Those individuals who elected to participate in the study were asked to read, sign the Informed Consent, and complete the written survey forms. Approximately five minutes were provided for the participants to read and sign the Informed Consent form, and the survey questionnaire required approximately fifteen minutes to complete. The total time needed to complete both forms was approximately twenty minutes. Participation in this study was completely voluntary. Participants were assured of their anonymity, and absolute confidentiality of their responses on the completed survey questionnaires.

\subsection{Sample}

Of a total of one hundred distributed questionnaires shown in Table 1, ninety-seven were returned; the response rate was $97 \%$. However, two were incomplete due to incomplete data.

Table 1. Frequency of distributed and returned questionnaire and response rate

\begin{tabular}{ccc}
\hline Mailed Questionnaire & Returned Questionnaire & Response Rate (\%) \\
\hline 100 & 97 & $97 \%$ \\
\hline
\end{tabular}

Participants included 95 adults (69 Males, 28 Females) ranging in age from 65 years to 96 years. The mean age of participants was 73.42 years. The sample, college educational level included, were elementary school (29.9\%), junior high school (30.9\%), High school diploma (15.5\%), Vocational or Junior college (11.3\%), some college (12.4\%), Bachelor's Degree (0\%), Master's Degree $(0 \%)$, and Doctorate $(0 \%)$. Their income level was $100 \%$ less than $\$ 19,999$. All the participants have children. The average number of children per participants was 6 children.

The participants' religion was Buddhism (69.1\%), Catholic (16.5\%), Cult of ancestors (7.2\%), Protestant (4.1\%), No religion (1.0\%), and Other ( $0 \%)$. The participants' time living in the Unites States of America included, less than 1 year $(1 \%)$, one to 5 years $(10.3 \%), 6$ to 10 years $(13.4 \%)$, and 11 years and over $(73.2 \%)$.

Ten items from the Life Satisfaction Index A (Neugarten, Havighurst, \& Tobin, 1961) were incorporated on the survey form to assess the first research objective: to understand the satisfaction level of older Vietnamese Americans who have been Acculturalized/Americanized for about 15 years. 


\section{Results}

\subsection{Life Satisfaction}

The total average score for the mean was 3.4210 and the standard deviation was .8739 with the scores ranging from 5 to 1 , higher scores indicating a greater level of satisfaction. With the mean of 3.4210 it shows that the older Vietnamese Americans are very well adjusted in the new country (Table 2). These findings are consistent with the findings of Shin and Johnson (1978), indicating that life satisfaction is a judgmental process, in which individuals judge the quality of their lives on the basis of their sole collection of standards. Life satisfaction is a deliberate cognitive opinion of one's life in which the standards for judgment are up to the individual. Life satisfaction is purely subjective and is established by an individual's emotional experience. Life satisfaction is said not to require health, prosperity, comfort, or high merit. Even so, Larson (1978) found a tremendous amount of support for a positive correlation between income and life satisfaction which is not true for the aging Vietnamese Americans since their annual income is among the lowest; they all live on welfare. Furthermore, in this present study, annual household income and life satisfaction were then compared and analyzed to determine whether individual's level of income influenced feelings of life satisfaction. Testing found no significant difference between men and women.

Table 2. Descriptive statistics of life satisfaction

\begin{tabular}{lccccc}
\hline Life satisfaction & $\mathrm{N}$ & Minimum & Maximum & Mean & Std. Deviation \\
\hline LSone & 95 & 1.00 & 5.00 & 3.4842 & .90933 \\
LStwo & 95 & 1.00 & 5.00 & 3.2000 & 1.04779 \\
LSthree & 95 & 1.00 & 5.00 & 3.0211 & .92229 \\
LSfour & 95 & 1.00 & 5.00 & 3.1368 & 1.03770 \\
LSfive & 95 & 2.00 & 5.00 & 3.6842 & .70353 \\
LSsix & 95 & 1.00 & 5.00 & 3.5579 & .83431 \\
LSseven & 95 & 2.00 & 5.00 & 3.7895 & .71302 \\
LSeight & 95 & 2.00 & 5.00 & 3.5158 & .82337 \\
LSnine & 95 & 1.00 & 5.00 & 3.1579 & .98192 \\
LSten & 95 & 1.00 & 5.00 & 3.6632 & .76646 \\
Total aver mean & & & & 3.4210 & .87390 \\
\hline
\end{tabular}

The following findings explore the second research objective: to measure the degree of obligations of adult children to their parents at 2 different time intervals. Paired samples t-tests were conducted to evaluate the objective.

Table 3 presents the descriptive statistics and the t-test result for the question: "Do you do this with your family during the week-ends (to go to some trip or restaurant).

Table 3. Paired samples statistics

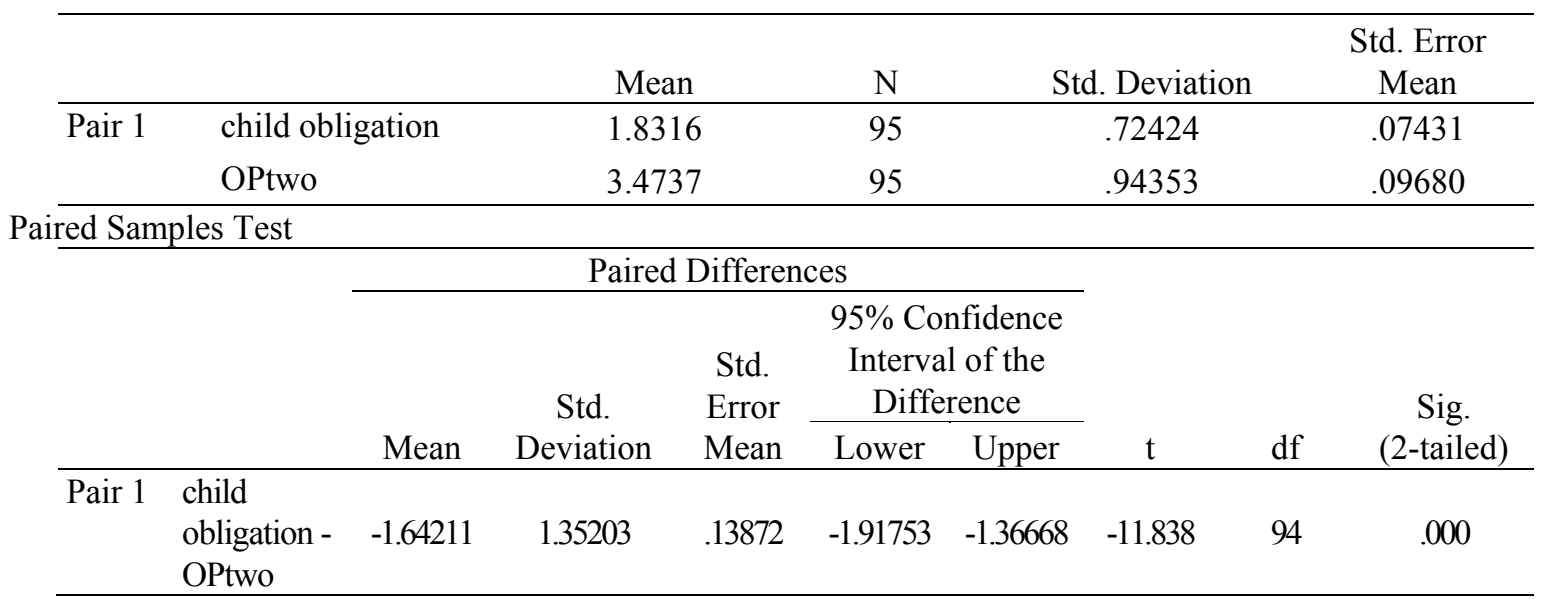

The $t$-test shows that there is a significant difference between the mean of the same question measuring the degree of obligations of adult children to their parents at 2 different time intervals. The children in the past did not consider going out on weekends as a way of showing love and responsibilities to their parents as the children who have been living in the USA. The children in the past had to obey and show compliance with their parents. This is 
consistent with the findings of Wilson 1970, 1981; Wui, 1985; Lin \& Fu 1990 which stress upon the socialization of Asian children into the values of Confucianism. Asian children learn that the greatest shame of all is to abandon one's parents, which is reinforced by school textbooks and by society at large. According to Confucianism, the harmonious family is crucial for a harmonious society and peaceful state; therefore, an obligation to parents is a central Confucian virtue, as is behaving according to one's rank and obligations within human relationships. The relationships include those between parent and child, husband and wife, elder and younger brothers, friend and friend, and ruler and subject. Of these relations, the first and foremost is that between parents and children, in which the primary responsibility for family harmony is mainly placed on the children. The conflict between different generations is reduced through the respect, reverence, and service which the younger provides to the elder. Children's respect and parent's love must be given for its own sake, and the fault of a parent should not be used as an excuse for his/her children not fulfilling their duties (Yao, 2000).

The next question asked was: "When you are sick, do your family members come to take care of you?" To make sure that among the Americanized/Acculturalized's transformations that were expected of the Vietnamese Americans children, the level of obligation to visit a sick parent was changed or transformed (Table 4).

Table 4. Paired samples statistics

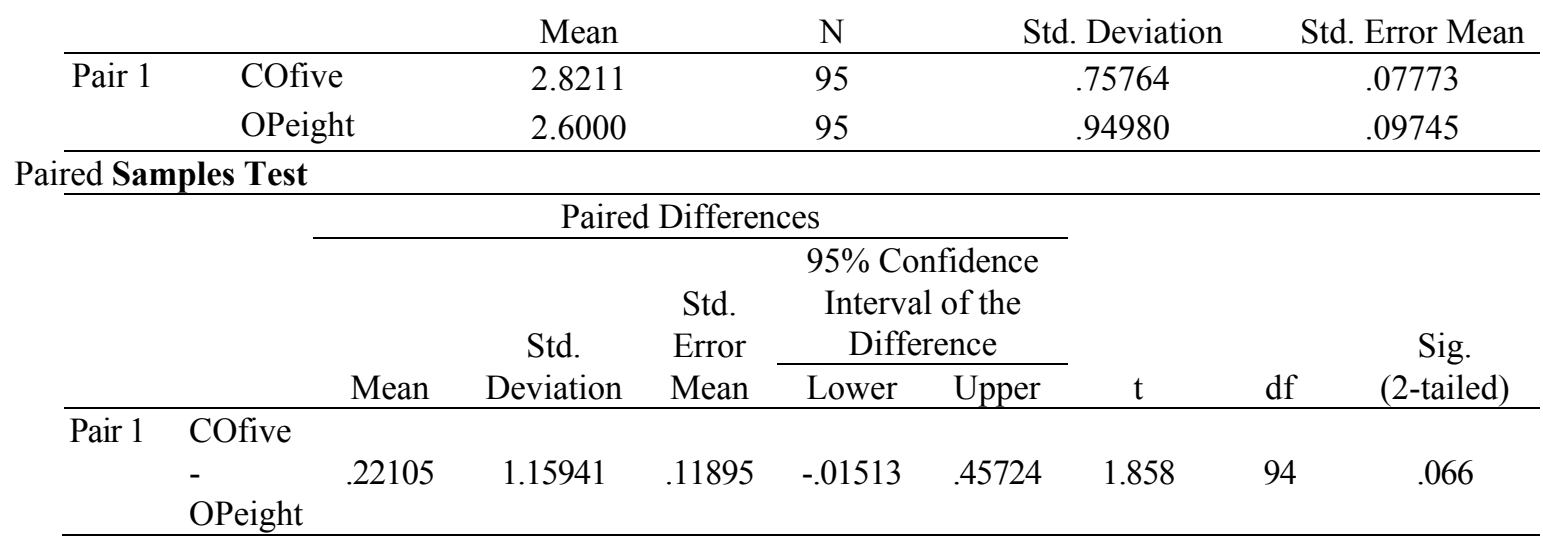

The $\mathrm{t}$-test shows that there is an insignificant difference with $\mathrm{t}=1.858, \mathrm{df}=94, \mathrm{p}=.066$. Taking care of the parents during their sickness is still being observed among the Vietnamese Americans children.

The following findings explore the third research objective: "To examine if there is a correlation between the level of Americanization/Acculturation of participants and adult children's obligations to their parents. Table 5 shows the questions of level of Americanization/Acculturation and the Descriptive statistics.

Table 5. Descriptive statistics

\begin{tabular}{lccccc}
\hline & $\mathrm{N}$ & Minimum & Maximum & Mean & Std. Deviation \\
\hline $\begin{array}{l}\text { level of } \\
\text { Americanization/accultur }\end{array}$ & 95 & 1.00 & 5.00 & 2.8000 & 1.12609 \\
ation & 95 & 2.00 & 5.00 & 3.9579 & .48192 \\
LAAtwo & 95 & 2.00 & 5.00 & 3.9053 & .65353 \\
LAAthree & & & & 3.554 & .752 \\
Total aver score & & & & \\
\hline
\end{tabular}

The total average score for the mean was 3.554 and the standard deviation was .752 with the score ranging from 5 to 1, higher scores indicating a greater level of Americanization. With the mean of 3.554 it shows that the older Vietnamese Americans are very well adjusted to the country.

A correlation analysis was conducted to examine if there is a correlation between the variable "acculturation" (I feel happy not living with my family) and the variable "obligation" (Your family members rarely visit you or cannot visit you and it its fine). 
Table 6. Correlations

\begin{tabular}{llcc}
\hline level of Americanization/acculturation & Pearson Correlation & 1 & .200 \\
& Sig. (2-tailed) & & .052 \\
& $\mathrm{~N}$ & 95 & 95 \\
\hline LAAtwo & Pearson Correlation & .200 & 1 \\
& Sig. (2-tailed) & .052 & \\
& $\mathrm{~N}$ & 95 & 95 \\
\hline
\end{tabular}

There is a very weak correlation between the 2 questions with sig (2-tailed) +.052 . Findings show that the respondents favored living alone and do not require family members to visit them on a regular basis. It also shows that the respondent's traditional family arrangements which required many generations living together were challenged in the face of new social forces. However, the findings are consistent with the assimilation perspective (Park, 1968) which suggested that immigrants groups were inevitably to move from attachment to "traditional" immigrant identities and culture toward integration into the "modern" mainstream of U.S. life. In other words, immigrant groups gradually became "Americanized," shedding their loyalties and connections with the immigrant culture and becoming assimilated into the melting pot of the United States. However, the findings are somewhat controversial with the results of the last question "When you are sick, does your family come right away to help you?" Respondents' children still come right away to help their parents when needed although they are supposed to be more "Americanized" than their parents. They are the ones who gained economic freedom due to the opportunities for wage employment in the industrialized society of the United States. It can be explained that the dichotomous and unitary concepts of "traditional" and "modern" are deeply problematic ways of understanding societies and social change. At the very least, it is too unrealistic and simple to assume a continuous and progressive unilinear movement from traditional values and behaviors to modern ones. Instead, scholars have argued that modernization processes are uneven: traditional values and social forms may co-exist in relative harmony with more modern ones.

It should be noted that the population of the Vietnamese Americans adults are very complex. For example, there are at least two generations over the age of 65 living in a same family. One may have both a great grandparent and a grandparent generation over the age of 65 . We know that, in general, the needs and circumstances of those aged approximately 80 years and over are often very different from those in their mid-sixties to mid/late seventies. These realities reflect the complexity of intergenerational ties and the problem of equating family roles (such as being a grandparent or being someone's adult child) with being in a particular group. The heterogeneity and broad diversity of the Vietnamese population aged 65 years older is very much lost by the usage of such terms as 'the elderly'.

\section{Discussion}

The findings of this study demonstrate a very high level of satisfaction of elderly Vietnamese Americans who have been Acculturalized/Americanized for about fifteen years. It shows that the Vietnamese Americans are very well adjusted in the new country. The obligations of adult children to their parents according to the ideology of Confucianism are still being observed although some traditional responsibilities like worshipping the ancestors have been curtailed. The aging Vietnamese Americans and their children are experiencing social, economic, and cultural challenges associated with a new life in the United States but they are struggling in ways that did not significantly alter their traditional familial obligations. In doing this, it demonstrates that they have brought with them a cultural luggage, or experiences and understandings about the world to the new society. They draw on pre-migration family experiences and ideologies in their efforts to construct families within the structural context of the new society.

While informal support is usually provided by family members, it is often provided by friends and neighbors as well. Most of the informal support received by older people is often provided by other elderly persons, usually spouses.

There is very little research which examines the diversity of family structures and dynamics in terms of race and ethnicity. However, it is important to consider how cultural norms involving filial obligation and expectations of family members as to appropriate responsibilities impact on the lives of elderly persons in diverse ethno-cultural contexts. The role of family members in facilitating access to culturally appropriate supports and services becomes especially vital in circumstances where language is the main barrier of the Vietnamese community. 


\subsection{Fictive Kin Ties}

As family life changes, with individuals becoming more geographically dispersed, and with large numbers of the population living into old age, enduring and socially supportive ties which may be characterized as "family-like" become of increasing importance in the life of the Vietnamese American adults. The term "fictive kin ties" (MacRae, 1992) is often used in this context. While very little is known about these kinds of ties among the Vietnamese population, their significance in the lives of older persons is evident. One study of the informal support networks of old people found that fully $15 \%$ of the "family" ties identified by older men and women did not involve ties of blood, marriage or adoption (Matthews, 1993). These close bonds, their place in the lives of older persons, and their significance in caregiving relationships remain largely outside current understandings of the personal and intimate relationships of older persons. For Vietnamese American adults, the rebuilding of kin groups was driven in part by the notion, embedded in the ideology of family collectivism, that kinship ties constituted an effective way of coping with economic scarcity and uncertainty, as they did in the past.

\subsection{Spousal and Filial Assistance}

The characteristic of the traditional Vietnamese family system suggests that it was shaped by a variety of cultural traditions. Among these traditions was Confucianism, which molded the inner core of family life, is offering a set of ideal standards and structures for kin relations. Confucian ideology, which shaped Vietnamese family life in critical ways, was predicated on the dominance of men over women and the complete submission of children to their parents. With their migration to the United States, this was no longer the case. The hierarchical vision of family life prescribed by Confucianism, one in which women were subordinate to men, as were the young to the old, was being threatened in serious ways by the conditions of life in the United States. Among the transformations that were expected of the Vietnamese families, perhaps the most fundamental was a movement toward greater generational and gender equality in families. Previously disenfranchised groups in the family --women and children--gained economic freedom due to the opportunities for wage employment in the industrialized society of the United States. Also relevant to the breakdown of the patriarchal family order was the more egalitarian quality of U.S. cultural values and patterns in contrast to Asian ones.

With this understanding of the broad range of sociodemographic changes which have characterized Vietnamese families in the United States in recent decades, one must ask the question about the consideration of family members for one another as they age? With aging, as family members experience changes in their work roles, their economic circumstances, and their physical, mental and social health, family relationships do change both between and across households. Over time, for members of the oldest generations, there will be shift along the continuum from independence to increasing dependence on others. The roles and responsibilities of the family members of elderly people may fluctuate, or change incrementally or dramatically (depending on the circumstances) from more reciprocal, often interdependent, episodic exchanges of aid, to the provision of regular, ongoing and needed assistance with physical and emotional needs.

The aging Vietnamese Americans are adapting themselves to denigrate various institutions, formal as well as informal, to survive in the new society. It may be understood as a reactive response of themselves to the conditions they encounter in the new society. However, the respondents in this study as well as their adult children are somewhat in their initial years of settlement in the United States, with the respondents' experience being exceptionally sharp at this period of time. In the years to come, as they become more acclimated to the social environment of the United States and gain more economic and social resources, it is likely that they will more closely resemble other ethnic groups that had come before them to the United States, especially when the family balance of power is shifted towards the children. Children had the opportunities to raise their voices to question previously hegemonic understandings of family. But for now, adult children within the Vietnamese family did not completely reject the traditional Vietnamese family system. Instead, they strived to rework it, to alter it in ways such that it meshed with the new challenges and circumstances of life in the United States.

\subsection{Implications}

As has been noted earlier, the character of the traditional Vietnamese family system suggests that it was shaped by a variety of cultural traditions. Among these traditions was Confucianism, which molded the inner core of family life. Confucianism has become an ideology almost universally practiced in Vietnam. Due to their recent immigration in the US, the Vietnamese might be deviated from Confucius ideology and adapted to American ideology.

As Ricoeur (1986) emphasized, ideology has the social function of providing justification of authority. In order for ideology to play its role, agreement of individuals in society is required. By using institutional vehicles - such as family, schools, politics, media, and other social institutions and national systems, ideology instills the agreement 
and consensus toward social order in people's consciousness. During a child's growth process, ideology, bolstered by familial and educational systems, is absorbed by the youngster. For the Vietnamese youngsters who were born in the United States, this may be due not only to societal norms during his/her childhood years but also to generational accumulation of American ideology; ideology can be passed on intergenerationally, modifying one generation by another. The changes in their familial structure, relationships, functions, obligations, and values may be unconsciously absorbed and accepted as natural. Did the Vietnamese Americans youngsters ever notice about these changes or, even worse, did they ever know that these ideologies exist? The role of the Vietnamese Americans is to make their children aware about the values of their "traditional" as well as the American ideologies and let them support or reject by themselves.

As Goode (1963) mentioned, American ideologies--democracy, individualism, and egalitarianism--might have been attractive for Vietnamese Americans. However, did Vietnamese Americans know that these ideologies would compromise their internal "traditional" family values in exchange for benefits and attractiveness? Ideologies may distort reality and may not be cognitive, analogous to non-indigenous plants which could ruin the equilibrium of ecology before it can be realized. Vietnamese Americans should think how to maintain, retrieve, or recreate social equilibrium.

The erosion of filial piety values has certainly taken place among Vietnamese Americans. It may affect not only family relations but also their communities and societies. For example, the power relationships within the family may change with decreasing parental authority, and parents may have increasing difficulties with home discipline and the inculcation of children's socialization; as a result, parents may become estranged from their children, and parents' reliance on other institutions may increase. The pattern of assistance to aging parents may change, and the needs for government interventions in elderly care may increase.

On the other hand, this filial piety value transformation perhaps should be seen as an inevitable process of readjustment of family and the moral order, reacting to social change. In normal social life, the widening gaps between beliefs and reality due to social changes can lead to discordances and contradictions among social norms and values. However, these discordances and contradictions may lead to formation of new social norms and values, which cope with the desires and ideals of members of society. The reformation may carry the possibility of producing a new equilibrium.

How will the Vietnamese Americans manage the widening gaps between reality and belief? Are they willing to live with the erosion of traditional family values and thus confront the costs of resulting problems? Or can they find any alternatives to family function, such as value socialization? Can social institutions help individuals to make their way without taking over family functions and to rescue those who have failed? What will the family function be? It may be inevitable for the family to follow social and ideological changes. Vietnamese Americans should watch their future families intently, contemplating what social roles the family should assume for the members of a family, as well as for society as a whole.

\section{References}

Eisen, A. (1984). Women and revolution in Vietnam. London: Zed Books Ltd., 103.

Goode, W. J. (1963). Word revolution and family patterns. New York: The Free Press.

Gordon, L. W. (1989). The missing children: Mortality and fertility in a South-East Asian refugee population. International Migration Review, 23(2), 228. http://dx.doi.org/10.2307/2546259

Hem, J. (1995). From Vietnam, Laos, and Cambodia: A refugee experience in the United States. New York: Twayne Publishers.

Kelly. (1998). From Vietnam to America,14; Jennifer Chang, interview by author, 14 February 1998. Elk Grove, California, tape recording; Hung and Haines, Refugees in America in the 1990s, 315.

Larson, R. (1978). Thirty years of research on the subjective well-being of older Americans. Journal of Gerontology, 33, 109-125.

Lawyers Committee for Human Rights. (1989). Refugee denied: Problems in the protection of Vietnamese and Cambodians in Thailand and the admission of Indochinese refugees in the United States. New York: Lawyers Committee for Human Rights.

Lee, R., Miller, T., \& Edwards, R. (2003, Feb.).The Growth and Aging of California's Population: Demographic and Fiscal Projections, Characteristics and Service Needs. CPRC Brief, 15(01).

Lin, C.Y.C., \& V. R. Fu. (1990). A comparison of child rearing practices among Chinese, immigrant Chinese, and Caucasian American parents. Child Development, 61, 429-33. http://dx.doi.org/10.2307/1131104 
MacRae, H. (1992). Fictive kin as a component of the social networks of older people. Research on Aging, 14(2), 226-247. http://dx.doi.org/10.1177/0164027592142004

Matthews, S. H., \& Rosner, T. T. (1988). Shared filial responsibility: The family as th primary caregiver. $J$. Marriage Fam, 50, 185-95. http://dx.doi.org/10.2307/352438

Neugarten, B. L., Havighurst, R. J., \& Tobin, S. S. (1961). The measurement of life satisfaction. Journal of Gerontology, 16, 134-143.

Park, R. E. (1968 [1916]). The city: Suggestions for the investigation of human behavior in the urban enviroment. In R. Sennet (Ed.), Classic essays on the culture of city (pp. 91-130). Englewood Cliffs, NJ: Prentice-Hall.

Ricoeur, P. (1986). Lectures on ideology and utopia. Edited by G. H. Taylor. New York: Columbia University Press.

Skinner, K. A. (1980). Vietnamese in America: Diversity in Adaptation. In Lawrence K.Hong and Ronald T. Tsukashima (Eds.), Asian/Pacific Americans: California Sociologist. A Journal of Sociology and Social Work, (p. 105, Vol. 3, No. 2). Los Angeles: California State University.

Wilson, R. W. (1981). Normal and Abnormal Behavior in Chinese Culture. Orlando, Fla: Academic Press.

Wui, P. (1985). Child training in Chinese culture. In Chinese culture and mental health. Orlando, Fla.: Academic Press.

Yao, S. (2000). Economic development and poverty alleviation in China under economic reform. Economic Development and Cultural Change, 48(3), 447-474. http://dx.doi.org/10.1086/452606 